\title{
Smoking, leisure-time exercise and frequency of self-reported common cold among the general population in northeastern China: a cross-sectional study
}

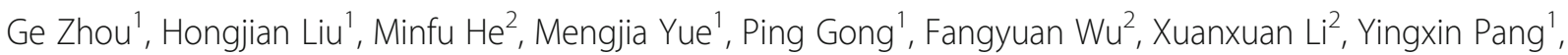
Xiaodi Yang ${ }^{1}$, Juan Ma², Meitian Liu', Jinghua Li ${ }^{2}$ and Xiumin Zhang ${ }^{2^{*}}$

\begin{abstract}
Background: Physical activity (PA) and smoking have been reported to be associated with the duration and severity of common cold symptoms. However, few studies have addressed the associations between the frequency of leisure-time exercise, cigarette smoking status and the frequency of the common cold in a cold area. This study was designed to investigate these issues in northeastern China.

Methods: This cross-sectional study included individuals who participated in a regular health examination conducted in Jilin Province, China. Information on episodes of the common cold, the frequency of leisure-time exercise and cigarette smoking status in the past year were collected by self-administered health questionnaires. Ordinal logistic regression models were used to analyse the associations between the frequency of leisure-time exercise, cigarette smoking status and the retrospective frequency of common cold.

Results: A total of 1413 employees participated in the study, with an average age of $38.92 \pm 9.04$ years and $44.4 \%$ of them were male. Of all participants, $80.8 \%$ reported having experienced the common cold in the past year. After adjustment, the risk of suffering from the common cold more than once (odds ratios (ORs), 1.59; 95\% confidence interval (CI), 1.27-1.99) in passive smokers was 1.59 times as high as that in non-smokers. Nevertheless, the results of the adjusted analysis showed no statistically significant relation between current smoking and the frequency of the common cold. A high frequency of leisure-time exercise ( $\geq 3$ days/week) was associated with a $26 \%$ reduced risk of having at least one episode of the common cold $(\mathrm{OR}, 0.74 ; 95 \% \mathrm{Cl}, 0.55-0.98)$ compared with a low frequency group ( $<4$ days/month). For current and passive smokers, the protective effect of a high frequency of leisure-time exercise appears not to be obvious (current smokers: OR, 0.68; 95\% Cl, 0.33-1.43; passive smokers: OR, 1.15; 95\% Cl, 0.69-1.93).
\end{abstract}

Conclusion: Passive smoking was associated with a higher risk of having self-reported common cold at least once, while a high frequency of leisure-time exercise was related to a lower risk of reporting more than one episode of the disease in Chinese.

Keywords: The common cold, Leisure-time exercise, Passive smoking, Smoking

\footnotetext{
* Correspondence: zhangxiumin63@163.com

${ }^{2}$ Department of Social Medicine and Health Management, School of Public

Health, Jilin University, Changchun, China

Full list of author information is available at the end of the article
} 


\section{Background}

As one of the most prevalent infectious illnesses, the common cold is estimated to occur an average of 2-5 times for adults and 6-10 times for children each year in the general healthy population [1]. It is usually thought that the common cold, although not a severe disease, is an infection attributed to more than 200 types of viruses or bacteria [2]. Causes of the common cold are difficult to be detected because of its various clinical symptoms and the variability of microbial virulence caused by antibiotic resistance [3, 4]. Therefore, effective prevention towards reduced clinical symptoms and duration of the common cold is still limited. The common cold also has the potential to bring those suffering from respiratory diseases a certain degree of difficulty in controlling and relieving their clinical symptoms, such as worsening asthma $[5,6]$ and chronic obstructive pulmonary disease (COPD) [7, 8]. Furthermore, the common cold is an issue that accounts for a substantial economic burden [9] and influences normal daily activities, such as low work productivity and absenteeism due to sickness [10-12].

Smoking and exercise are modifiable lifestyle factors of maintaining health. Both smoking and passive smoking were not only related to an increased risk of various malignancies [13-15] and degenerative disorders of the cardiovascular system $[16,17]$ but also associated with an increased predisposition to developing the upper respiratory tract infections (URTIs) by microbial pathogens [18-24]. Although previous studies have examined the relationship between passive smoking and the incidence of the common cold in women and children [21-23], few studies have examined the association in the general population. The relationships of active smoking, severity of active smoking and frequency of common cold remain controversial and remain to be confirmed.

Physical activity (PA) was also associated with a susceptibility to URTI, but most existing studies have been performed in the elderly [25-27] and athletes [28, 29]. It has been suggested that the risk of URTI was increased for individuals engaging in extreme physical exertion [29, 30]. However, little is known about effects of moderate-intensity levels of exercise on the frequency of the common cold in predominately nonathletic population. In comparison with athletes and elders, individuals in the general individuals, especially the occupational population, are more likely to engage in moderate levels of leisure-time exercise and have less leisure-time to exercise regularly. Thus, examining the role of leisure-time exercise could urge young and middle-aged individuals to exercise, to some extent.

Northeastern of China is thought to be at high risk of respiratory disease, mainly due to exposure to the cold air in the long winter season [31], air pollutants caused by winter coal-fired heating [32-34] and inadequate vitamin D, which can affect immune function due to fewer outdoor activities in winter [35]. Therefore, the main objective of this study was to examine the influences of active or passive cigarette smoking and the frequency of leisure-time exercise on the retrospective frequency of the common cold in a cold area in northeastern China. Furthermore, we further explore the potential interaction between leisure-time exercise and cigarette smoking status on the common cold.

\section{Methods \\ Participants}

This cross-sectional study was conducted at the medical examination centre of the First Hospital of Jilin University, northeastern China, from June to September in 2016. All staff members of banks participating in regular physical examinations were invited to participate during the study period. The study followed a common set of procedures, which included physical examinations, blood and urine screenings and self-administered health questionnaires. A total of 1530 employees accepted the invitation to participated in the questionnaire survey. Of these 1530 employees, the data of 69 employees were excluded because of missing data, and that of 48 retirees were also excluded, which resulted in a final sample size of 1413 for the present analyses. The data were collected from regular medical examination reports and self-administered questionnaires in these employees. All participants were given informed consent prior to being enrolled in the study. Characteristics of the participants are reported in Tables 1 and 2 .

\section{Common cold}

The common cold was assessed with a single item: "How many times were you infected with the common cold in the previous year?" Response options included none, one, two, and three or more times, similar to prior studies [21, 36, 37]. We told participants about the definition and general clinical symptoms of the common cold [2] to help participants distinguish the common cold from flu-like illness and allergies before the health questionnaire survey. The frequency of the common cold was divided into four categories (none, one, two, three or more times) for analysis.

\section{Health-related behaviours}

On the health questionnaires, participants were asked to choose their smoking status in the past year from the following options: non-active smoker, past smoker and current smoker. In addition, current smokers were required to answer an open-ended item: "How many cigarettes did you smoke per day in the past year?" Participants were also required to answer whether they were passively exposed to tobacco smoke by inhaling smog for more than $15 \mathrm{~min}$ at least once a week. In our study, we categorized current smokers as light smokers ( $<15$ cigarettes/day) and heavy smokers ( $\geq 15$ cigarettes/day). Past smokers were considered to be those who quit more than one year ago, while those who quit less than one year ago were regarded as current 
Table 1 Sample basic characteristics according to the categorized cigarette smoking status

\begin{tabular}{|c|c|c|c|c|c|c|}
\hline \multirow[t]{2}{*}{ Variables } & \multirow{2}{*}{$\begin{array}{l}\text { Sample } \\
(n=1413)\end{array}$} & \multicolumn{5}{|c|}{ Cigarette smoking categories } \\
\hline & & $\begin{array}{l}\text { Non-smokers } \\
(n=641)\end{array}$ & $\begin{array}{l}\text { Passive smokers } \\
(n=476)\end{array}$ & $\begin{array}{l}\text { Past smokers } \\
(n=82)\end{array}$ & $\begin{array}{l}\text { Light current smokers } \\
(n=113)\end{array}$ & $\begin{array}{l}\text { Heavy current smokers } \\
(n=101)\end{array}$ \\
\hline \multicolumn{7}{|l|}{ Gender, $\mathrm{n}(\%)^{* *}$} \\
\hline Male & $627(44.4)$ & 185(28.9) & 155(32.6) & $78(95.1)^{\Delta}$ & $108(95.6)^{\Delta}$ & $101(100.0)^{\Delta}$ \\
\hline Age, $y^{* *}$ & $38.92 \pm 9.04$ & $38.07 \pm 8.83$ & $38.63 \pm 9.32$ & $43.95 \pm 8.0^{\Delta}$ & $38.81 \pm 8.81$ & $41.75 \pm 8.36^{\triangle}$ \\
\hline \multicolumn{7}{|l|}{ Ethnicity, n (\%) } \\
\hline Han & 1293(91.5) & $591(92.2)$ & $426(89.5)$ & 75(91.5) & 107(94.7) & $94(93.1)$ \\
\hline \multicolumn{7}{|l|}{ Education levels, n (\%)* } \\
\hline Senior school or less & $83(5.9)$ & $33(5.1)$ & $23(4.8)$ & $11(13.4)$ & $8(7.1)$ & $8(7.9)$ \\
\hline Junior college & $326(23.1)$ & 137(21.4) & $113(23.7)$ & $23(28.0)$ & $24(21.2)$ & $29(28.7)$ \\
\hline Bachelor degree & $799(56.5)$ & $365(56.9)$ & $270(56.7)$ & $42(51.2)$ & $64(56.6)$ & $58(57.4)$ \\
\hline Master degree or greater & $205(14.5)$ & $106(16.5)$ & $70(14.7)$ & $6(7.3)^{\Delta}$ & $17(15.0)$ & $6(5.9)$ \\
\hline$B M I^{* *}$ & $23.90 \pm 5.36$ & $23.70 \pm 6.89$ & $23.20 \pm 3.52$ & $25.90 \pm 3.2^{\Delta}$ & $25.60 \pm 3.21^{\triangle}$ & $25.40 \pm 3.26^{\triangle}$ \\
\hline \multicolumn{7}{|c|}{ Frequency of drinking (days/week), n (\%)** } \\
\hline 0 & $859(60.8)$ & $481(75.0)$ & 293(61.6) & $26(31.7)$ & $24(21.2)$ & $35(34.7)$ \\
\hline $1-2$ & $468(33.1)$ & $143(22.3)$ & $165(34.7)$ & $47(57.3)$ & $69(61.1)$ & $44(43.6)$ \\
\hline$\geq 3$ & $86(6.1)$ & $17(2.7)$ & $18(3.8)^{\Delta}$ & $9(11.0)^{\Delta}$ & $20(17.7)^{\Delta}$ & $22(21.8)^{\Delta}$ \\
\hline \multicolumn{7}{|l|}{ Sleep duration, $n(\%)^{* *}$} \\
\hline$<7$ hours & $402(28.5)$ & $168(26.2)$ & $130(27.3)$ & $22(26.8)$ & $52(46.0)$ & $30(29.7)$ \\
\hline $7-8$ hours & $561(39.7)$ & 243(37.9) & 195(41.0) & $37(45.1)$ & $38(33.6)$ & $48(47.5)$ \\
\hline$\geq 8$ hours & $450(31.8)$ & 230(35.9) & 151(31.7) & $23(28.0)$ & $23(20.4)^{\Delta}$ & 23(22.8) \\
\hline \multicolumn{7}{|l|}{ SRSS, n (\%) } \\
\hline$\geq 23$ & $594(42.0)$ & 257(40.1) & 215(45.2) & $25(30.5)$ & $52(46.0)$ & $45(44.6)$ \\
\hline \multicolumn{7}{|l|}{ Self-rated health, n (\%) } \\
\hline Poor & 168(11.9) & $67(10.5)$ & $61(12.8)$ & $7(8.5)$ & $15(13.3)$ & 18(17.8) \\
\hline Fair & $718(50.8)$ & $317(49.5)$ & $244(51.3)$ & $45(54.9)$ & $66(58.4)$ & $46(45.5)$ \\
\hline Good & $527(37.3)$ & $257(40.1)$ & 171(35.9) & $30(36.6)$ & $32(28.3)$ & $37(36.6)$ \\
\hline \multicolumn{7}{|c|}{ Self-perceived life stress, $n(\%)^{* *}$} \\
\hline Low & $217(15.4)$ & 108(16.8) & $69(14.5)$ & 14(17.1) & $12(10.6)$ & $14(13.9)$ \\
\hline Fair & $751(53.1)$ & $370(57.7)$ & $243(51.1)$ & $43(52.4)$ & $49(43.4)$ & $46(45.5)$ \\
\hline High & $445(31.5)$ & $163(25.4)$ & $164(34.5)^{\Delta}$ & $25(30.5)$ & $52(46.0)^{\Delta}$ & $41(40.6)^{\Delta}$ \\
\hline \multicolumn{7}{|c|}{ Self-perceived work stress, $\mathrm{n}(\%)^{*}$} \\
\hline Low & 165(11.7) & $76(11.9)$ & $56(11.8)$ & $12(14.6)$ & $12(10.6)$ & $9(8.9)$ \\
\hline Fair & $615(43.5)$ & $306(47.7)$ & 183(38.4) & $40(48.8)$ & $42(37.2)$ & $44(43.6)$ \\
\hline High & $633(44.8)$ & 259(40.4) & $237(49.8)^{\Delta}$ & 30(36.6) & $59(52.2)$ & $48(47.5)$ \\
\hline \multicolumn{7}{|l|}{ SAS, n (\%)* } \\
\hline$\geq 50$ & 219(15.5) & $87(13.6)$ & $89(18.7)$ & $7(8.5)$ & $15(13.3)$ & $21(20.8)$ \\
\hline \multicolumn{7}{|l|}{ SDS, n (\%)* } \\
\hline$\geq 50$ & $561(39.7)$ & 236(36.8) & $200(42.0)$ & 28(34.1) & $45(39.8)$ & $52(51.5)^{\Delta}$ \\
\hline$N E^{* *}$ & $3.78(3.10,4.56)$ & $3.70(3.07,4.49)$ & $3.73(3.00,4.47)$ & $3.56(3.09,4.33)$ & $3.94(3.22,4.69)$ & $4.78(3.84,5.76)^{\Delta}$ \\
\hline $\mathrm{MO}^{* *}$ & $0.29(0.21,0.39)$ & $0.28(0.21,0.37)$ & $0.29(0.22,0.39)$ & $0.30(0.21,0.39)$ & $0.30(0.21,0.42)$ & $0.42(0.28,0.51)^{\Delta}$ \\
\hline$L Y^{* *}$ & $2.15(1.83,2.54)$ & $2.13(1.81,2.52)$ & $2.10(1.77,2.43)$ & $2.14(1.80,2.50)$ & $2.25(1.97,2.77)^{\Delta}$ & $2.47(2.10,2.87)^{\Delta}$ \\
\hline
\end{tabular}

Values are shown as the mean \pm SD or median (interquartile range) for continuous data and number and proportions for categorical data $P$-values were calculated by analysis of variance or Kruskal-Wallis $H$ tests for continuous variables and $X^{2}$-tests for categorical variables Superscript numbers denote statistically significant post hoc tests: ${ }^{\Delta} \leq 0.05 / 4$ for the difference between current, past, passive smokers and non-smokers. Current, past and passive smokers were compared with non-smokers

* Statistical significance: $P<0.05$

**Statistical significance: $P<0.001$ 
Table 2 Sample basic characteristics according to the categorized frequency of leisure-time exercise

\begin{tabular}{|c|c|c|c|c|}
\hline \multirow[t]{2}{*}{ Variables } & \multirow{2}{*}{$\begin{array}{l}\text { Sample } \\
(\mathrm{n}=1413)\end{array}$} & \multicolumn{3}{|c|}{ Frequency of leisure-time exercise } \\
\hline & & $\begin{array}{l}\text { Low }(<4 \text { days/month }) \\
(N=375)\end{array}$ & $\begin{array}{l}\text { Medium (1-2 days/week }) \\
(N=624)\end{array}$ & $\begin{array}{l}\text { High }(\geq 3 \text { days/week }) \\
(N=414)\end{array}$ \\
\hline \multicolumn{5}{|l|}{ Gender, n (\%) $)^{* *}$} \\
\hline Male & $627(44.4)$ & $141(34.1)$ & 285(45.7) & 201(53.6) \\
\hline Age, $y^{* *}$ & $38.92 \pm 9.04$ & $35.25 \pm 7.55$ & $38.44 \pm 8.73$ & $43.79 \pm 8.94$ \\
\hline \multicolumn{5}{|l|}{ Ethnicity, n (\%)* } \\
\hline Han & 1293(91.5) & $370(89.4)$ & $571(91.5)$ & 352(93.9) \\
\hline \multicolumn{5}{|l|}{ Education levels, n (\%)** } \\
\hline Senior school or less & $83(5.9)$ & $10(2.4)$ & $36(5.8)$ & $37(9.9)$ \\
\hline Junior college & $326(23.1)$ & $80(19.3)$ & $147(23.6)$ & $99(26.4)$ \\
\hline Bachelor degree & $799(56.5)$ & $268(64.7)$ & $336(53.8)$ & 195(52.0) \\
\hline Master degree or greater & $205(14.5)$ & $56(13.5)$ & 105(16.8) & $44(11.7)$ \\
\hline$\left.B M\right|^{* *}$ & $23.90 \pm 5.36$ & $23.10 \pm 3.95$ & $24.30 \pm 6.92$ & $24.40 \pm 3.18$ \\
\hline \multicolumn{5}{|c|}{ Drinking categories (days/week), n (\%)* } \\
\hline 0 & $859(60.8)$ & $270(65.2)$ & $365(58.5)$ & 224(59.7) \\
\hline $1-2$ & $468(33.1)$ & $125(30.2)$ & $223(35.7)$ & $120(32.0)$ \\
\hline$\geq 3$ & $86(6.1)$ & 19(4.6) & $36(5.8)$ & $31(8.3)$ \\
\hline \multicolumn{5}{|l|}{ Sleep duration, $\mathrm{n}(\%)^{*}$} \\
\hline$<7$ hours & $402(28.5)$ & $115(27.8)$ & 168(26.9) & 119(31.7) \\
\hline $7-8$ hours & $561(39.7)$ & 153(37.0) & $256(41.0)$ & $152(40.5)$ \\
\hline$\geq 8$ hours & 450(31.8) & $146(35.3)$ & $200(32.1)$ & $104(27.7)$ \\
\hline \multicolumn{5}{|l|}{ SRSS, n (\%) } \\
\hline$\geq 23$ & $594(42)$ & 189(45.7) & $260(41.7)$ & $145(38.7)$ \\
\hline \multicolumn{5}{|l|}{ Self-rated health, n (\%) } \\
\hline Poor & 168(11.9) & $82(19.8)$ & $59(9.5)$ & $27(7.2)$ \\
\hline Fair & $718(50.8)$ & $216(52.2)$ & $353(56.6)$ & 149(39.7) \\
\hline Good & $527(37.3)$ & 116(28.0) & 212(34.0) & 199(53.1) \\
\hline \multicolumn{5}{|c|}{ Self-perceived life stress, n (\%)* } \\
\hline Low & 217(15.4) & $52(12.6)$ & $82(13.1)$ & $83(22.1)$ \\
\hline Fair & $751(53.1)$ & $217(52.4)$ & $356(57.1)$ & $178(47.5)$ \\
\hline High & $445(31.5)$ & 145(35.0) & 186(29.8) & 114(30.4) \\
\hline \multicolumn{5}{|c|}{ Self-perceived work stress, n (\%) } \\
\hline Low & $165(11.7)$ & $30(7.2)$ & $56(9.0)$ & $79(21.1)$ \\
\hline Fair & $615(43.5)$ & $171(41.3)$ & 292(46.8) & $152(40.5)$ \\
\hline High & 633(44.8) & 213(51.4) & $276(44.2)$ & 144(38.4) \\
\hline \multicolumn{5}{|l|}{ SAS, n (\%) $)^{* *}$} \\
\hline$\geq 50$ & $219(15.5)$ & $92(22.2)$ & $87(13.9)$ & $40(10.7)$ \\
\hline \multicolumn{5}{|l|}{ SDS, n (\%)* } \\
\hline$\geq 50$ & $561(39.7)$ & 188(45.4) & 238(38.1) & 135(36.0) \\
\hline $\mathrm{NE}^{*}$ & $3.78(3.10,4.56)$ & $3.83(3.21,4.72)$ & $3.82(3.10,4.57)$ & $3.64(2.97,4.36)$ \\
\hline MO & $0.29(0.21,0.39)$ & $0.29(0.21,0.38)$ & $0.30(0.21,0.40)$ & $0.29(0.21,0.40)$ \\
\hline LY & $2.15(1.83,2.54)$ & $2.16(1.81,2.52)$ & $2.15(1.84,2.56)$ & $2.12(1.81,2.51)$ \\
\hline
\end{tabular}

Values are shown as the mean \pm SD or median (interquartile range) for continuous data and number and proportions for categorical data $P$-values were calculated by analysis of variance or Kruskal-Wallis $H$ tests for continuous variables and trend $X^{2}$-tests for categorical variables * Statistical significance: $P<0.05$

**Statistical significance: $P<0.001$ 
smokers. Passive smokers were defined as those who had never smoked but were exposed to tobacco smoke. Current, past and passive smokers were compared with non-smokers who were non-active smokers without exposure to passive smoking. The status of cigarette smoking and the number of cigarettes were self-reported by the participants investigated in the study.

Leisure-time exercise was assessed according to an item designed by a reference to the National Health Interview Survey (NHIS) [38]: "Outside of work or daily activities, how often have you exercised per week in the past year that at least moderately increased your breathing and heart rate for at least 20 minutes?" The frequency of leisure-time exercise was divided into three categories: high ( $\geq 3$ days/week), medium (1-2 days/ week) and low ( $<4$ days/month). Intensity and patterns of leisure-time exercise were not recorded.

In the survey, participants were also required to report on drinking alcohol and engaging in alcohol abstinence, as well as on their frequency of drinking. With regard to the frequency of alcohol consumption, these participants chose one of the following four options: 0 days/week, 1-2 days/ week, 3-5 days/week and 6-7 days/week. We combined data on the frequency of alcohol intake into three categories (0 days/week, 1-2 days/week and $\geq 3$ days/week) for analysis. Average sleep duration at night was assessed by asking participants how many hours they slept on average at night. Sleep duration was categorized into three groups: $<7,7-8$ and $\geq 8 \mathrm{~h}$. Sleep quality was measured by a continuous score based on 10 five-point items on the SelfRating Scale of Sleep (SRSS). A score of more than 23 points indicates poor sleep according to the standard in SRSS (Cornbash's alpha $=0.64)$ [39]. Previous study have confirmed the reliability and validity of SRSS for evaluating sleep quality in the Chinese population [40].

\section{Psychological measures}

The Chinese versions of the Self-Rating Depression Scale (SDS) [41] and the Self-Rating Anxiety Scale (SAS) [42], prepared by Zung in 1965 and 1971, respectively, were used to measure depressive and anxious symptoms. Both measures comprised 20 self-reported items, and each item was scored on a 4-point scale. Increasing scores suggested an increasing severity of anxiety or depression symptoms. The criterion of having depressive or anxious symptoms was determined as a standardized score of 50 or more out of 80 points. Previous studies have confirmed the reliability and validity of the SDS and the SAS (Cronbach's alpha $=0.85)$ for used in the Chinese population $[43,44]$.

Self-rated health (SRH) was measured by asking participants what they think of their health status in the previous year, with response options of very poor, poor, fair, good and very good. In addition, life and work stresses were evaluated with two questions as follows: 1) How do you feel about your work stress in the previous year? 2) How do you feel about your life stress in the previous year? Response options for the two questions included very low, low, fair, high and very high. Due to small numbers in several categories, we combined data on groups of SRH, self-rated life stress and self-rated work stress into three categories, respectively (SRH: poor, fair and good; life or work stress: low, fair and high).

\section{Biomarkers}

Biomarkers (lymphocyte (LY), neutrophil (NE) and monocyte $(\mathrm{MO})$ ) of the participants were collected from regular medical examination reports.

\section{Standard control variables}

Information on gender (female/male), age (continuous), ethnicity (dichotomized as Han/other), education levels, weight and height were collected using health questionnaires and health examinations. Educational levels were categorized into senior high school or less, junior college, bachelor's degree and master's degree or greater. Body mass index (BMI) was calculated as weight $/$ height $^{2}\left(\mathrm{~kg} / \mathrm{m}^{2}\right)$.

\section{Statistical analysis}

The data were presented as means \pm standard deviations (SD), medians (interquartile ranges) or number (proportions). Trend $\chi^{2}$-tests or $\chi^{2}$-tests for categorical variables and analyses of variance (ANOVA) or Kruskal-Wallis $H$ tests for continuous variables were used to assess the differences in basic characteristics according to the categorized cigarette smoking status and frequency of leisuretime exercise. Post hoc analysis was conducted by the Bonferroni correction. Because the dependent variable of the frequency of the common cold had been classified into four categories according to their order of magnitude, ordinal logistic regression models were used to analyse the associations between cigarette smoking status, the frequency of leisure-time exercise and self-reported frequency of the common cold in the previous year. The odds ratios (ORs) and 95\% confidence intervals (CI) were adjusted with the following potential confounding factors: gender, age, ethnicity, education levels, BMI, drinking status, sleep duration, SRSS, SRH, self-perceived work stress, self-perceived life stress, SAS, SDS, LY, NE and MO. The rationale for including these covariates in the model is that they could potentially affect the relationship of main variables (cigarette smoking status and the frequency of leisure-time exercise) and the common cold. ORs and 95\% CI were calculated as $\exp ^{(\text {b) }}$. The criterion for statistical significance was set at $P<0.05$. The data were analysed using SPSS Statistics for Windows, version 22.0 (IBM Corp, Armonk, New York, USA). 


\section{Results}

\section{Basic characteristics}

In this study, male employees accounted for $44.4 \%$ of the sample. Of all participants, $80.8 \%$ reported catching a common cold in the past year, and $37.2 \%, 31.6 \%$ and $12.1 \%$ experienced the common cold during the previous year once, twice, and three or more times, respectively. The prevalence of the common cold was almost similar between genders $(79.7 \%$ for males and $81.7 \%$ for females, $P=0.359)$. Similarly, there were no statistically significant gender differences in the frequency of the common cold $(P=0.274)$.

Table 1 shows the basic characteristics (standard controls variables, health-related behaviours, psychological measures and biomarkers) for the participants according to the categorized cigarettes smoking status. The results of the study indicate that almost all current smokers were males (97.7\%), and the number of passive smokers in women was almost twice as high as that in men. Past, heavy current smokers ( $\geq 15$ cigarettes/day) were older than non-smokers. Current smokers reported a higher proportion of highfrequency daily alcohol intake ( $\geq 3$ days/week) and high life stress than non-smokers, and a relative increase in having depressive symptoms ( $S D S \geq 50$ ) appeared only for the heavy/non-smokers. They had higher values for BMI and LY. Additionally, higher prevalences of high-frequency daily alcohol intake, high work stress and high life stress were found in passive smokers than in non-smokers.

Table 2 presents characteristics of the sample across the low, medium and high leisure-time exercise groups. Groups differed on the standard control variables. BMI, age, the proportion of males, and the number of participants of Han ethnicity, Junior college or lower education level and high frequency of daily alcohol intake ( $\geq 3$ days/week) increased across low to high groups. In contrast, there were reductions in the percentages of participants having psychological problems (having high life or work stress and having anxious ( $\mathrm{SAS} \geq 50$ ) or depressive ( $\mathrm{SDS} \geq 50$ ) symptoms), reporting poor quality and sleeping more than $8 \mathrm{~h}$ with an increase in the frequency of leisure-time exercise. Higher-frequency exercisers reported a lower value of NE.

\section{Cigarettes smoking status and the common cold}

The proportions of participants who had the common cold more than once by cigarette smoking status (non-smokers, passive smokers, past smokers, light current smokers, heavy current smokers) were $78.5 \%, 85.7 \%, 78.0 \%, 78.8 \%$, and $77.2 \%$, respectively (data not shown). Table 3 and Fig. 1 show that the percentages of having more than two episodes of the common cold in passive, past and current smokers were higher than that in non-smokers, while the relationship between past or current smoking and the frequency of the common cold was not significant.

Table 4 presents ORs and their 95\% CI from ordinal logistic regression analyses, with the frequency of the common cold as the dependent variable. After adjustment for gender and age, the likelihood of suffering from at least one episode of the common cold was higher in passive smokers than in non-smokers (Table 4, Model 1: OR, 1.64; 95\%CI, 1.32-2.03; $P<0.001)$. To determine whether other potential factors accounted for the association, we entered SRSS, SRH, healthrelated behaviours, psychological variables and biomarkers into ordinal logistic regression model, including cigarette smoking status and standard control variables. We observed that passive smokers had 1.59 times odds of experiencing the common cold more than once compared with non-smokers (Table 4, Model 2: OR, 1.59; 95\%CI, 1.27-1.99; $P<0.001$ ), and the addition of these variables did not appreciably influence the association. Nevertheless, the relationship between past or current smoking and the disease appears to be not obvious (Model 2: past smokers: OR, 1.32; 95\%CI, 0.84-2.09; $P=0.229$; light current smokers: $\mathrm{OR}, 1.05 ; 95 \% \mathrm{CI}, 0.70-1.59$; $P=0.801$; heavy current smokers: OR, 1.26 ; $95 \% \mathrm{CI}, 0.81-$ 1.96; $P=0.295)$.

\section{Physical activity and the common cold}

When retrospective episodes of the common cold were divided by leisure-time exercise groups, at least one episode of the common cold was reported by $84.8 \%$ of the low group ( $<3$ days/month), $82.4 \%$ of the medium group (1-2 days/week), and $73.9 \%$ of the high group ( $\geq 3$ days/ week) (data not shown). Table 3 and Fig. 2 show the trend of an increase in the percentage of people who had not caught a cold in the previous year with increasing frequency of leisure-time exercise, while there was an inverse trend for the proportion of individuals experiencing three or more episodes of the common cold.

Inspection of the ORs adjusted for gender and age reveals a significant association between the risk of the common cold and the frequency of leisure-time exercise. The risk of experiencing more than one episode of the common cold during a 12-month prospective period was $36 \%$ lower in the high vs. low exercise groups (Table 4, Model 1 high group: OR, 0.64; 95\%CI, 0.48-0.84; $P=$ $0.001)$. After multivariable adjustment, the high group of leisure-time exercise was associated with a $26 \%$ reduced risk of having at least one episode of the common cold in comparison to the low group. Inclusion of these variables resulted in a $10.0 \%$ increment in the OR of leisuretime exercise associated with self-reported common cold in the high vs. low groups for leisure-time exercise levels, but a relevant effect size remained robust (Model 2 high group: OR, 0.74; 95\%CI, 0.55-0.98; $P=0.035)$.

\section{The effect of the interaction between leisure-time exer- cise and cigarette smoking on the common cold}

Table 5 presents the risk of the common cold for leisuretime exercise by cigarette smoking status. These results indicate that an inverse association between the high group 
Table 3 Smoking status and frequency of leisure-time exercise according to the categorized frequency of common cold

\begin{tabular}{|c|c|c|c|c|c|c|}
\hline \multirow[t]{2}{*}{ Variables } & \multirow{2}{*}{$\begin{array}{l}\text { Sample } \\
(n=1413)\end{array}$} & \multicolumn{4}{|c|}{ Frequency of common cold ${ }^{a}$} & \multirow[t]{2}{*}{ P-value } \\
\hline & & $0(n=271)$ & $1(n=525)$ & $2(n=446)$ & $\geq 3(n=171)$ & \\
\hline \multicolumn{7}{|l|}{ Cigarette smoking categories } \\
\hline Non-smokers & 641 & $138(21.5)$ & 256(39.9) & $178(27.8)$ & $69(10.8)$ & - \\
\hline Passive smokers & 476 & $68(14.3)$ & $163(34.2)$ & 178(37.4) & $67(14.1)$ & $<0.001$ \\
\hline Past smokers & 82 & $18(22.0)$ & $30(36.6)$ & $24(29.3)$ & 10(12.2) & 0.715 \\
\hline Light current smokers & 113 & $24(21.2)$ & $42(37.2)$ & $37(32.7)$ & 10(8.8) & 0.790 \\
\hline Heavy current smokers & 101 & $23(22.8)$ & $34(33.7)$ & $29(28.7)$ & 15(14.9) & 0.443 \\
\hline \multicolumn{7}{|c|}{ Frequency of leisure-time exercise } \\
\hline Low $<4$ days/month & 414 & $63(15.2)$ & 155(37.4) & 132(31.9) & $64(15.5)$ & - \\
\hline Medium 1-2 days/week & 624 & 110(17.6) & $233(37.3)$ & 205(32.9) & $76(12.2)$ & 0.206 \\
\hline High $\geq 3$ days/week & 375 & $98(26.1)$ & $137(36.5)$ & 109(29.1) & $31(8.3)$ & $<0.001$ \\
\hline
\end{tabular}

${ }^{a}$ Episodes of self-reported common cold in the previous year

Values are shown as numbers and proportions for categorical data

$P$-values were calculated by ordinal logistic regression

Statistical significance: $P<0.05$

of leisure-time exercise and the risk of experiencing at least one episode of the common cold was significant in nonsmokers (OR, 0.54; 95\%CI, 0.35-0.84; $P=0.006$ ), especially in women (OR, 0.48; 95\%CI, 0.28-0.80; $P=0.005)$. For past smokers, the protective effect of a high frequency of leisure-time exercise appears to approach marginal significance (OR, 0.22; 95\%CI, 0.05-0.96; $P=0.045$ ), while the frequency of leisure-time exercise was found to have no statistically significant influence on the risk of the common cold in current and passive smokers. (current smokers: OR, 0.68; 95\%CI, 0.33-1.43; $P=0.313$; passive smokers: $\mathrm{OR}$, $1.15 ; 95 \%$ CI, 0.69-1.93; $P=0.595$ ).

\section{Discussion}

Poor sleep, poor self-rated health, mental stress, anxious symptoms and depressive symptoms are risk factors of URTI, as confirmed in other studies [27, 45-47]. However, compared with these factors, lifestyle strategies for URTI prevention can be relatively easy to implement and have received consistent scientific supports. We combined data from the cross-sectional study revealing that passive smoking and a high frequency of leisure-time exercise ( $\geq 3$ days/week) were important correlates of the retrospective frequency of the common cold in the general population. The association was independent of sociodemographic, SRSS, SRH, health-related behaviours, psychological variables and biomarkers.

We found that the probability of suffering from at least one episode of the common cold during the previous year was higher in passive smokers than in non-smokers, while the impact of active smoking on the frequency of the common cold was not observed. The results were similar to other investigations of the association between cigarette smoking and RTI $[21,48]$. In the trial by Bensenor and his

\section{$\mathbf{\Delta} \mathbf{N} 1 \mathbf{2} \square \geq 3$}

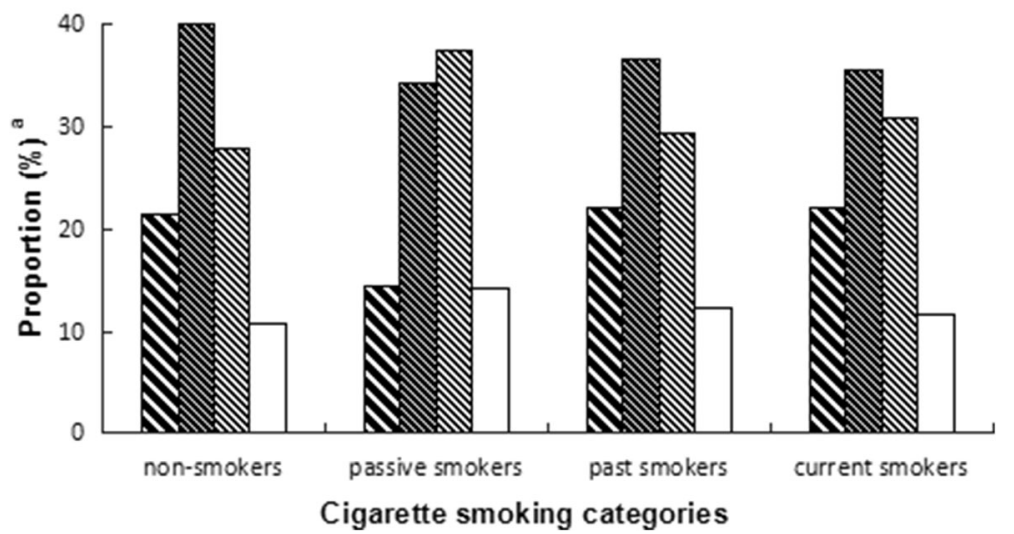

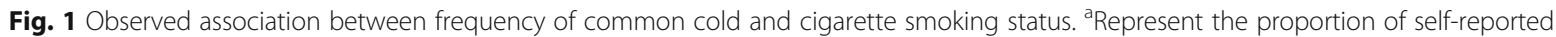
common cold in the categorized cigarette smoking 
Table 4 Results of ordinal logistic regression analyses for the related factors of the common cold ${ }^{a}$

\begin{tabular}{|c|c|c|c|c|c|c|}
\hline \multirow[t]{3}{*}{ Variables } & \multicolumn{6}{|c|}{ Statistical ordinal logistic parameters } \\
\hline & \multicolumn{3}{|c|}{ Model $1^{\mathrm{b}}$} & \multicolumn{3}{|c|}{ Model $2^{c}$} \\
\hline & $\bar{\beta}$ & $\mathrm{OR}(95 \% \mathrm{Cl})$ & P-value & $\bar{\beta}$ & $\mathrm{OR}(95 \% \mathrm{Cl})$ & $P$-value \\
\hline \multicolumn{7}{|l|}{ Cigarette smoking categories } \\
\hline Non-smokers & & Ref & & & Ref & \\
\hline Passive smokers & 0.49 & $1.64(1.32-2.03)$ & $<0.001$ & 0.46 & $1.59(1.27-1.99)$ & $<0.001$ \\
\hline Past smokers & 0.29 & $1.34(0.85-2.10)$ & 0.207 & 0.28 & $1.32(0.84-2.09)$ & 0.229 \\
\hline Light current smokers & 0.18 & $1.19(0.80-1.77)$ & 0.384 & 0.05 & $1.05(0.70-1.59)$ & 0.801 \\
\hline Heavy current smokers & 0.33 & $1.39(0.92-2.11)$ & 0.121 & 0.24 & $1.26(0.81-1.96)$ & 0.295 \\
\hline \multicolumn{7}{|c|}{ Frequency of leisure-time exercise } \\
\hline Low (< 4 days/month) & & Ref & & & Ref & \\
\hline Medium (1-2 days/week) & -0.11 & $0.89(0.71-1.13)$ & 0.344 & -0.04 & $0.96(0.76-1.22)$ & 0.764 \\
\hline High ( $\geq 3$ days/week) & -0.45 & $0.64(0.48-0.84)$ & 0.001 & -0.31 & $0.74(0.55-0.98)$ & 0.035 \\
\hline
\end{tabular}

appisodes of self-reported common cold in the previous year

Ordinal logistic regression models were used to analyse the association of cigarette smoking status, frequency of leisure-time exercise and self-reported frequency of common cold

${ }^{\mathrm{b}}$ Adjusted models control for gender and age

'Adjusted models control for gender, age, ethnicity, education levels, BMI, frequency of drinking, sleep duration, SRSS, SRH, self-perceived life stress, self-perceived work stress, SAS, SDS, LY, NE and MO

Statistical significance: $P<0.05$

colleagues in 2001 [21], the risk of more frequent colds was higher for women who were non-smokers with passively exposed to cigarette smoking (RR, 1.33; 95\%CI, $1.18-1.51)$, while current light ( $<25$ cigarettes/day) (RR, $0.94 ; 95 \% \mathrm{CI}, 0.81-1.10)$ and heavy ( $\geq 25$ cigarettes/day) (RR, 1.17; 95\%CI, 0.81-1.10) smokers had no appreciable association with the frequency of common cold relative to women who were non-smokers without exposed to passive smoke. German and his colleagues also indicated that they did not find an association between smoking and symptomatic respiratory infection in a cohort of military recruits in Greece [48]. In addition, previous studies performed in children provide some supports for an impact, such that children who were exposed to environmental tobacco smoke had higher risk for URTI than children who lived in a smoke-free environment [22, 23].

Nevertheless, the findings presented should be interpreted with caution. Although we data fail to show that there was an increase in the frequency of the common cold in active smokers, previous studies indicated that increased damages by URTI in active smokers were attributable to increased duration and severity of the URTI symptoms $[19,21]$ and the restricted the efficacy of antiinfectious therapy $[18,49]$. Furthermore, other earlier experimental and epidemiological studies observed that active smokers had a higher incidence of URTI $[24,50]$.

The discrepancy shown in our study might be explained by the limitation that the proportion of active smokers was too

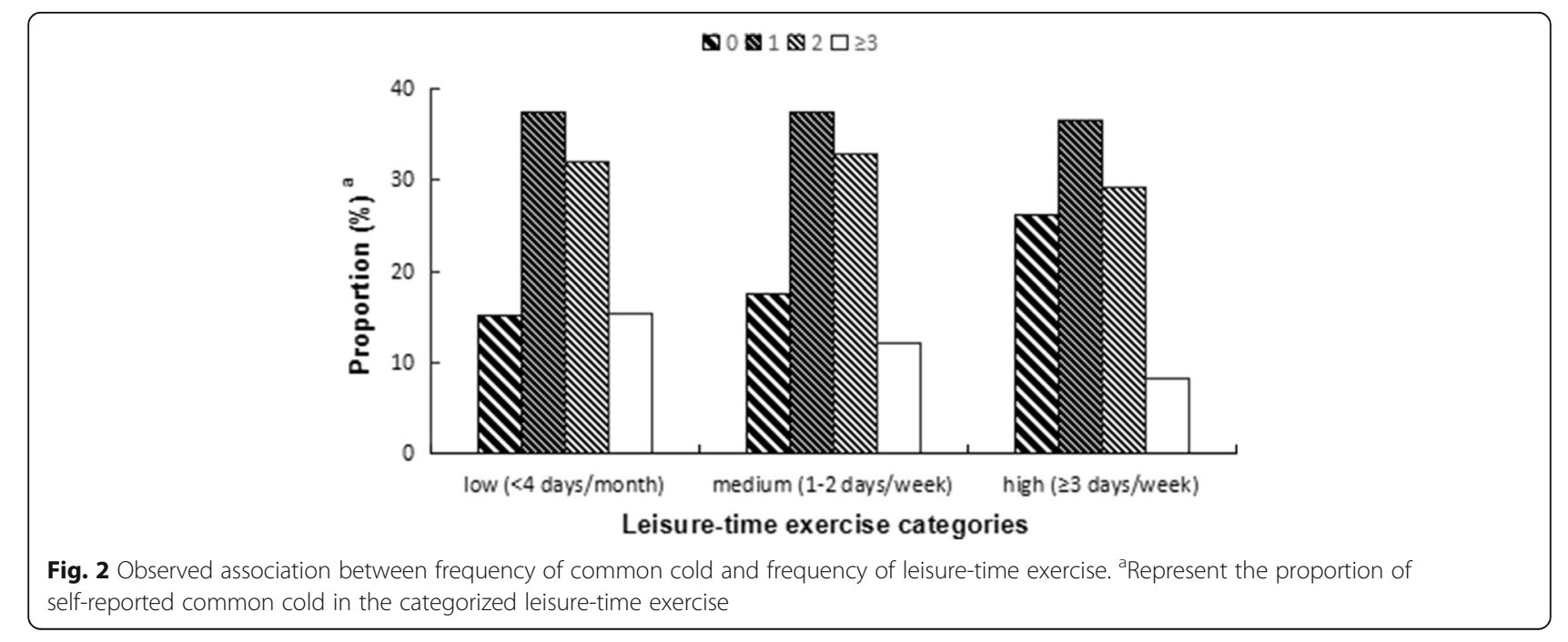




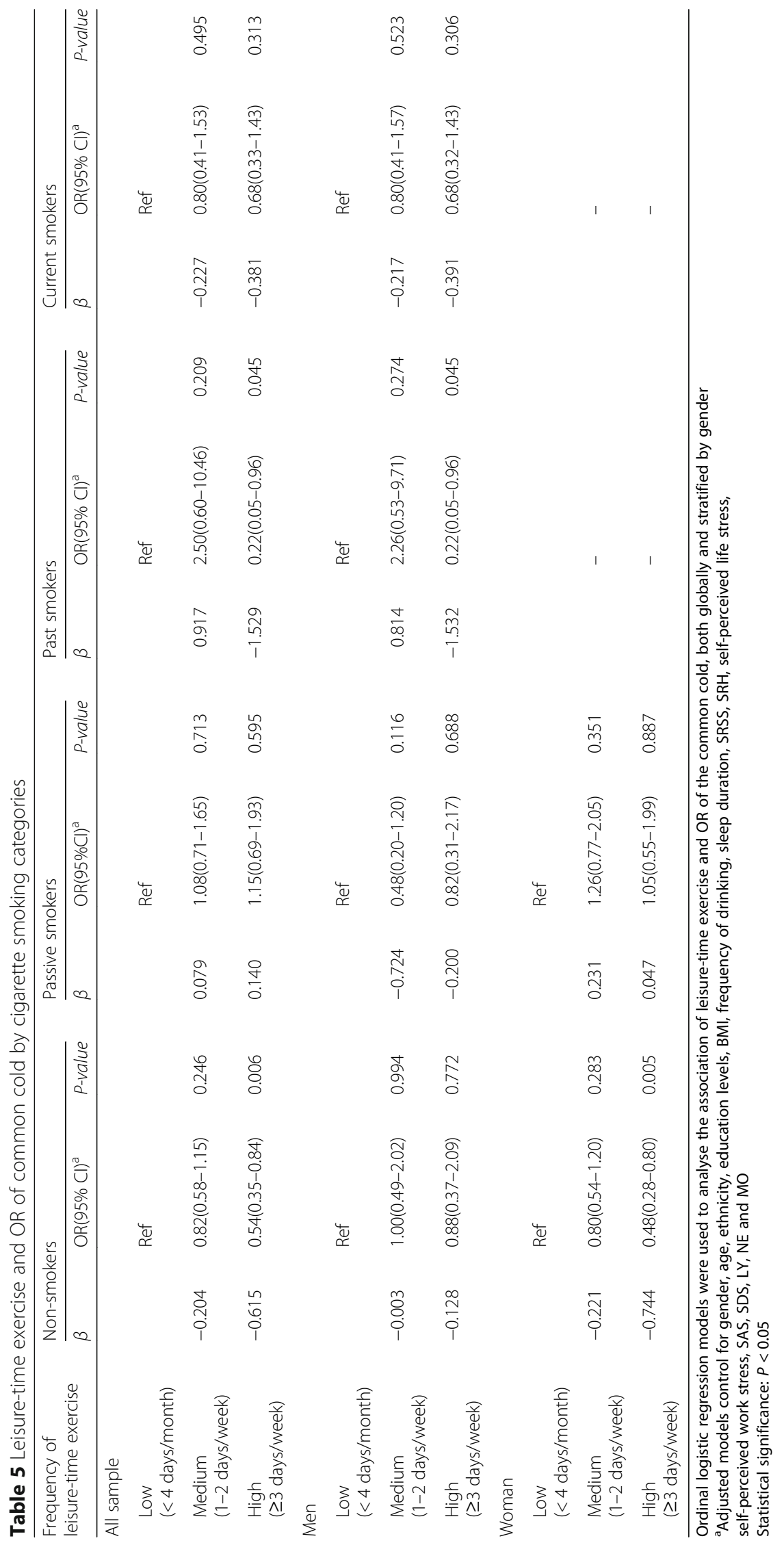


low (15.1\%), which may have led to a false negative association for current smokers. To determine whether active smoking is a risk factor for the frequency of common cold, a sufficiently large sample size is needed to be collected in our study.

Another possible explanation for the results is that passive smokers mainly absorbed side-stream tobacco smoke drifting from lit cigarettes, and there were higher concentrations of toxic gases, including ammonia and dimethylnitrosamine, in side-stream than in mainstream smoke inhaled by active smokers $[18,51]$. It has been reported that fresh side-stream smoke at concentrations commonly encountered indoors is well above the $2 \mathrm{mg} / \mathrm{m}^{3}$ reference concentration, and the level can cause respiratory tract epithelium damage [52]. In addition, non-smokers were more vulnerable to effects of tobacco smoke than past and current smokers [21], because their cardiopulmonary function is probably less "adaptable to tobacco smoke". Tobacco smoke has a suppressive effect on the protective functions of immunocyte and adaptive immune mechanisms, and had a direct effect on microbial pathogens to enhance the probability of infectious disease, specifically promoting microbial virulence and antibiotic resistance $[18,53]$.

Regular moderate PA enhanced resistance to URTI, which can reduce the number of episodes, clinical symptoms and duration of URTI $[27,36,54]$. A cohort study performed in healthy adults aged $20-70$ years indicated that there was a "J"-shaped relationship of PA and the risk of URTI, and high levels of moderate-vigorous activity were associated with a reduced risk for URTI relative to low levels of activity [36]. An epidemiological study conducted by Nieman et al. showed that the frequency of near-daily aerobic activity was correlated with reduced severity and duration with URTI symptoms during a 12-week period [54]. By contrast, among the frail elderly nursing home population, a 32-week exercise intervention was not associated with a change in the incidence of URTI [26]. Moreover, an earlier study performed in elderly women also concluded that 12 weeks of moderate cardiorespiratory exercise did not bring about an improvement in immune function [25].

Our study supported the opinion that in the general healthy Chinese population, leisure-time moderate exercise at least three times per week was inversely related to the risk of experiencing at least one episode of the common cold, while a """-shaped association between leisure-time moderate and the risk of the common cold was not found. Given that the participants investigated in our study were staff members at a bank, a professional population, few individuals performed heavy physical labour or had an opportunity to participate in high levels of exercise training. Thus, the effects of high levels of exercise training on the risk of the common cold could not be found, as implied by the latter part of the "I"- shaped curve. Findings from the investigation demonstrated that the risk of having one or more episodes of the common cold was reduced by $26 \%$ in the high vs. low groups of leisure-time exercise after controlling for confounders. A four months follow-up period in the general population aged 20-60 years showed that high levels of PA $(\geq 55 \mathrm{MET} \cdot \mathrm{h} \bullet \mathrm{d}-1)$ were associated with an $18 \%$ reduced risk (IRR, 0.82; 95\% CI, 0.69-0.98) of self-reported URTI compared with low level group $(<45 \mathrm{MET} \bullet \mathrm{h} \bullet \mathrm{d}-1)$ [55]. A study of the symptomatology of URTI and habitual PA performed in elderly indicated that the risk for having at least three URTI episodes per year was $9 \%$ lower in subjects with higher 7-day recall moderate scores (OR, 0.91; 95\% CI, $0.83-0.99)$ [27]. The reduction in the risk of the common cold with a high frequency of leisure-time exercise had more significance in our study is probably because the individuals we investigated are predominately nonathletic adults with sedentary lifestyle. Moderate PA has been deemed to improve immune competence in a manner, and the mechanisms for the effect of moderate exercise on the reduction of URTI risk are still being explored and debated. The physiological mechanism might be explained by the fact that immune system function is partially enhanced via increasing the activity of natural killer cells and the function of superior $T$ cells [56]. Moreover, recent data suggest that moderateintensity exercise can increase the secretion of immunoglobulin (Ig) A [57, 58], and salivary IgA plays a major role in the human mucosal immune system [59].

In addition, our data indicate that a high frequency of leisure-time exercise was associated with a reduced risk of experiencing at least one episode of the common cold in non-smokers, and the protective effect of a high level of leisure-time exercise appears to approach marginal significance in past smokers. However, we did not see that leisuretime exercise reduced the negative effects of cigarette smoke on common cold risk, as suggested by Hemila et al. [60]. The findings in their study showed that moderate PA had no material association with a lower common cold risk in middle-aged male smokers. A study performed in postmenopausal women compared moderate-intensity exercise individuals with those engaging in stretching sessions, finding that the incidence of URTI can be reduced in non-smoking women [61]. In contrast, the abovementioned study conducted by Fondell et al. indicated that a high level of PA was associated with a reduced risk of self-reported common cold for both smokers and non-smokers [55]. This difference is possibly explained by the fact that the association between leisure-time exercise and the common cold was modified by smoking status. Passive smokers were at a relatively high risk, irrespective of how much exercise they performed. Non-smokers and past smokers have eliminated the negative effects of cigarette smoke on the common cold. Therefore, the risk of the common cold was reduced as the frequency of moderate exercise increased. It is noteworthy that this phenomenon was not observed in current smokers. Considering that previous studies have confirmed the effect 
of active smoking on cold symptoms [19, 21], it is necessary to further explore the association between active smoking and the frequency of the common cold in our study.

Several shortcomings of the present study should be acknowledged. First, it was an observational study that relied on self-reports of the common cold without confirmation by laboratory examination. However, it is the subjective symptoms that affect the individual's life and work status, and therefore the subjective outcome is more relevant for the purpose of public health [60]. Furthermore, episodes of the common cold and the exposure to main variables (leisure-time exercise and cigarettes smoking status) were also self-reported. Therefore, recall bias may exist in the process of information collection. Second, the associations among common cold risk and the intensity, duration and types of leisure-time exercise patterns, as well as the impact of daily activities, were not analysed. In fact, as mentioned before, considering the professional nature of participants investigated in our study, the likelihood of engaging in extreme intensity of leisure-time exercise would be slim. Third, we controlled for the SRH, SRSS, sociodemographic variables, psychological variables, biomarkers and other health-related behaviours, but there were still other possibilities we had not covered, for instance, the number of people with whom the participants may share an office or apartment and the health status of apartment mates and colleagues [62].

\section{Conclusion}

In summary, our study revealed that passive smoking was associated with higher risk of having at least one episode of a self-reported common cold during the previous year. Nevertheless, active smoking was not significantly related to the frequency of the common cold. In addition, a high frequency of leisure-time exercise ( $\geq 3$ days/week) in the general population of healthy adults was associated with a lower risk of experiencing the self-reported common cold more than once than a low frequency group. For smokers and passive smokers, the protective effect of a high level of leisure-time exercise on the risk of the common cold does not appear to be obvious.

\section{Abbreviations}

BMI: Body mass index; LY: Lymphocyte; MO: Monocyte; NE: Neutrophil; PA: Physical activity; SAS: Self-Rating Anxiety Scale; SDS: Self-Rating Depression Scale; SRH: Self-rated health; SRSS: Self-Rating Scale of Sleep

\section{Acknowledgments}

This work was supported by the medical examination centre of the First Hospital of Jilin University. We are grateful to all participants who participated in the health examination and agreed to be included in the study.

\section{Funding}

This study was supported by Jilin Provincial Science and Technology Grant, China (No. 201105074). Xiumin Zhang received the funding. The funders had no role in the study design, data collection and analysis, decision to publish, or preparation of the manuscript.

\section{Availability of data and materials}

The datasets used and analysed during the current study are available from the corresponding author on reasonable request.

\section{Authors' contributions}

$X Z$ and $H L$ conceived and designed the study. GZ, MY, PG, FW, XL, YP, XY, $J M$ and $M L$ conducted the field study and data management. GZ, HL and $\mathrm{MH}$ analysed and interpreted the data. GZ drafted the manuscript. XZ, HL, $\mathrm{MH}$ and $J \mathrm{~L}$ participated in revising the manuscript. All authors read and approved the final manuscript.

\section{Ethics approval and consent to participate}

This study was reviewed and approved by the Ethics Committee of Jilin University School of Public Health (No.2015-12-08), and written informed consent was obtained from all subjects before they participated in the study.

\section{Consent for publication}

Not applicable.

\section{Competing interests}

The authors declare that they have no competing interests.

\section{Publisher's Note}

Springer Nature remains neutral with regard to jurisdictional claims in published maps and institutional affiliations.

\section{Author details}

${ }^{1}$ Department of Epidemiology and Biostatistics, School of Public Health, Jilin University, Changchun, China. ${ }^{2}$ Department of Social Medicine and Health Management, School of Public Health, Jilin University, Changchun, China.

Received: 31 August 2017 Accepted: 22 February 2018

Published online: 27 February 2018

References

1. Monto AS. Epidemiology of viral respiratory infections. Am J Med. 2002; 112(Suppl 6A):4S-12S.

2. Heikkinen T, Jarvinen A. The common cold. Lancet (London, England). 2003; 361(9351):51-9.

3. Vinogradova KA, Bulgakova VG, Polin AN, Kozhevin PA. Microbial antibiotic resistance: resistome, its volume, diversity and development. Antibiot Khimioter. 2013;58(5-6):38-48.

4. Alpuche C, Garau J, Lim V. Global and local variations in antimicrobial susceptibilities and resistance development in the major respiratory pathogens. Int J Antimicrob Agents. 2007;30(Suppl 2):S135-8.

5. Walter MJ, Castro M, Kunselman SJ, Chinchilli VM, Reno M, Ramkumar TP, Avila PC, Boushey HA, Ameredes BT, Bleecker ER, et al. Predicting worsening asthma control following the common cold. Eur Respir J. 2008;32(6):1548-54.

6. Corne JM, Marshall C, Smith S, Schreiber J, Sanderson G, Holgate ST, Johnston SL. Frequency, severity, and duration of rhinovirus infections in asthmatic and non-asthmatic individuals: a longitudinal cohort study. Lancet (London, England). 2002;359(9309):831-4.

7. Varkey JB, Varkey B. Viral infections in patients with chronic obstructive pulmonary disease. Curr Opin Pulm Med. 2008;14(2):89-94.

8. Decramer M, Janssens W, Miravitlles M. Chronic obstructive pulmonary disease. Lancet (London, England). 2012;379(9823):1341-51.

9. Bramley TJ, Lerner D, Sames M. Productivity losses related to the common cold. J Occup Environ Med. 2002;44(9):822-9.

10. Dicpinigaitis PV, Eccles R, Blaiss MS, Wingertzahn MA. Impact of cough and common cold on productivity, absenteeism, and daily life in the United States: ACHOO survey. Curr Med Res Opin. 2015;31(8):1519-25.

11. Roelen CA, Koopmans PC, Notenbomer A, Groothoff JW. Job satisfaction and short sickness absence due to the common cold. Work (Reading, Mass). 2011;39(3):305-13.

12. Nakata A, Takahashi M, Irie M, Ray T, Swanson NG. Job satisfaction, common cold, and sickness absence among white-collar employees: a cross-sectional survey. Ind Health. 2011;49(1):116-21.

13. Zhi XY, Zou XN, Hu M, Jiang Y, Jia MM, Yang GH. Increased lung cancer mortality rates in the Chinese population from 1973-1975 to 2004-2005: an adverse health effect from exposure to smoking. Cancer. 2015;121(Suppl 17):3107-12. 
14. Stayner L, Bena J, Sasco AJ, Smith R, Steenland K, Kreuzer M, Straif K. Lung cancer risk and workplace exposure to environmental tobacco smoke. Am J Public Health. 2007;97(3):545-51.

15. Park S, Jee SH, Shin HR, Park EH, Shin A, Jung KW, Hwang SS, Cha ES, Yun $\mathrm{YH}$, Park SK, et al. Attributable fraction of tobacco smoking on cancer using population-based nationwide cancer incidence and mortality data in Korea. BMC Cancer. 2014;14:406.

16. Nakamura K, Nakagawa H, Sakurai M, Murakami Y, Irie F, Fujiyoshi A, Okamura T, Miura K, Ueshima H, Group E-JR. Influence of smoking combined with another risk factor on the risk of mortality from coronary heart disease and stroke: pooled analysis of 10 Japanese cohort studies. Cerebrovasc Dis. 2012;33(5):480-91.

17. Lightwood JM, Coxson PG, Bibbins-Domingo K, Williams LW, Goldman L. Coronary heart disease attributable to passive smoking: CHD policy model. Am J Prev Med. 2009;36(1):13-20.

18. Feldman C, Anderson R. Cigarette smoking and mechanisms of susceptibility to infections of the respiratory tract and other organ systems. J Infect. 2013;67(3):169-84.

19. Cohen S, Tyrrell DA, Russell MA, Jarvis MJ, Smith AP. Smoking, alcohol consumption, and susceptibility to the common cold. Am J Public Health. 1993;83(9):1277-83.

20. Gryczynska D, Kobos J, Zakrzewska A. Relationship between passive smoking, recurrent respiratory tract infections and otitis media in children. Int J Pediatr Otorhinolaryngol. 1999;49(Suppl 1):S275-8.

21. Bensenor IM, Cook NR, Lee IM, Chown MJ, Hennekens CH, Buring JE, Manson JE. Active and passive smoking and risk of colds in women. Ann Epidemiol. 2001;11(4):225-31.

22. Chatzimicael A, Tsalkidis A, Cassimos D, Gardikis S, Spathopoulos D, Tripsianis GA, Kambouri K, Aivazis V, Vaos G, Bouros D. Effect of passive smoking on lung function and respiratory infection. Indian J Pediatr. 2008;75(4):335-40.

23. Fernandez-Plata R, Rojas-Martinez R, Martinez-Briseno D, Garcia-Sancho C, Perez-Padilla R. Effect of passive smoking on the growth of pulmonary function and respiratory symptoms in schoolchildren. Rev Invest Clin. 2016; 68(3):119-27.

24. Galvan Fernandez C, Suarez Lopez de Vergara RG, Oliva Hernandez C, Domenech Martinez E. Respiratory disease in young people and smoking. Archivos de bronconeumologia. 2000;36(4):186-90.

25. Nieman DC, Henson DA, Gusewitch G, Warren BJ, Dotson RC, Butterworth DE, Nehlsen-Cannarella SL. Physical activity and immune function in elderly women. Med Sci Sports Exerc. 1993;25(7):823-31.

26. Kapasi ZF, Ouslander JG, Schnelle JF, Kutner M, Fahey JL. Effects of an exercise intervention on immunologic parameters in frail elderly nursing home residents. J Gerontol A Biol Sci Med Sci. 2003;58(7):636-43.

27. Kostka T, Praczko K. Interrelationship between physical activity, symptomatology of upper respiratory tract infections, and depression in elderly people. Gerontology. 2007;53(4):187-93.

28. Robson-Ansley P, Howatson G, Tallent J, Mitcheson K, Walshe I, Toms C, DUT G, Smith M, Ansley L. Prevalence of allergy and upper respiratory tract symptoms in runners of the London marathon. Med Sci Sports Exerc. 2012; 44(6):999-1004.

29. Nieman DC. Immune function responses to ultramarathon race competition. Medicina Sportiva. 2009;13(4):189-96.

30. Tiollier E, Gomez-Merino D, Burnat $\mathrm{P}$, Jouanin JC, Bourrilhon C, Filaire E, Guezennec CY, Chennaoui M. Intense training: mucosal immunity and incidence of respiratory infections. Eur J Appl Physiol. 2005;93(4):421-8.

31. Mourtzoukou EG, Falagas ME: Exposure to cold and respiratory tract infections. International Journal of Tuberculosis \& Lung Disease the Official Journal of the International Union Against Tuberculosis \& Lung Disease 2007, 11(9):938-943.

32. Teng $B$, Zhang $X$, Yi C, Zhang $Y$, Ye S, Wang Y, Tong DQ, Lu B. the association between ambient air pollution and allergic rhinitis: further epidemiological evidence from Changchun, northeastern China. Int J Environ Res Public Health. 2017;14(3)

33. Dong GH, Qian Z, Liu MM, Wang D, Ren WH, Fu Q, Wang J, Simckes M, Ferguson TF, Trevathan E. Obesity enhanced respiratory health effects of ambient air pollution in Chinese children: the seven northeastern cities study. Int J Obes (Lond). 2013;37(1):94-100.

34. Tam WW, Wong TW, Ng L, Wong SY, Kung KK, Wong AH. Association between air pollution and general outpatient clinic consultations for upper respiratory tract infections in Hong Kong. PLoS One. 2014;9(1):e86913.

35. Gleeson M. Immunological aspects of sport nutrition. Immunol Cell Biol. 2016;94(2):117-23.
36. Matthews CE, Ockene IS, Freedson PS, Rosal MC, Merriam PA, Hebert JR. Moderate to vigorous physical activity and risk of upper-respiratory tract infection. Med Sci Sports Exerc. 2002;34(8):1242-8.

37. Ouchi E, Niu K, Kobayashi Y, Guan L, Momma H, Guo H, Chujo M, Otomo A Cui Y, Nagatomi R. Frequent alcohol drinking is associated with lower prevalence of self-reported common cold: a retrospective study. BMC Public Health. 2012;12:987.

38. Parsons VL, Moriarity C, Jonas K, Moore TF, Davis KE, Tompkins L. Design and estimation for the national health interview survey, 2006-2015. Vital Health Stat 2. 2014(165):1-53.

39. JM L, SF Y, JX D, QB Z: Analysis rating of sleep state of 13273 normal persons. Health Psychol J 2000(03):351-353. (in Chinese).

40. Liu C, Xie H, Zhang X, Yu Y, Zhang X, Sun Y, Zhou L, Su B, Wang H. Health related management plans improve sleep disorders of patients with chronic liver disease. Int J Clin Exp Med. 2015:8(6):9883-9.

41. Zung WW. A self-rating depression scale. Arch Gen Psychiatry. 1965;12:63-70,

42. Zung WW. A rating instrument for anxiety disorders. Psychosomatics. 1971; 12(6):371-9.

43. Zhou J, Yang Y, Qiu X, Yang X, Pan H, Ban B, Qiao Z, Wang L, Wang W. Relationship between anxiety and burnout among Chinese physicians: a moderated mediation model. PLoS One. 2016;11(8):e0157013.

44. Xu L, Ren J, Cheng M, Tang K, Dong M, Hou X, Sun L, Chen L. Depressive symptoms and risk factors in Chinese persons with type 2 diabetes. Arch Med Res. 2004;35(4):301-7.

45. Cohen S, Doyle WJ, Alper CM, Janicki-Deverts D, Turner RB. Sleep habits and susceptibility to the common cold. Arch Intern Med. 2009;169(1):62-7.

46. Park SG, Kim HC, Min JY, Hwang SH, Park YS, Min KB. A prospective study of work stressors and the common cold. Occup Med (Lond). 2011:61(1):53-6.

47. Cohen S, Janickideverts D, Doyle WJ. Self-rated health in healthy adults and susceptibility to the common cold. Psychosom Med. 2015;77(9):959.

48. German V, Kopterides P, Poulikakos P, Giannakos G, Falagas ME. Respiratory tract infections in a military recruit setting: a prospective cohort study. J Infect Public Health. 2008:1(2):101-4.

49. Bagaitkar J, Demuth DR, Scott DA. Tobacco use increases susceptibility to bacterial infection. Tob Induc Dis. 2008:4:12.

50. Mohren DC, Swaen GM, Borm PJ, Bast A, Galama JM. Psychological job demands as a risk factor for common cold in a Dutch working population. J Psychosom Res. 2001;50(1):21-7.

51. Behera SN, Xian H, Balasubramanian R. Human health risk associated with exposure to toxic elements in mainstream and sidestream cigarette smoke. Sci Total Environ. 2014:472:947-56.

52. Schick S, Glantz S. Philip Morris toxicological experiments with fresh sidestream smoke: more toxic than mainstream smoke. Tob Control. 2005; 14(6):396-404.

53. Arcavi L, Benowitz NL. Cigarette smoking and infection. Arch Intern Med. 2004;164(20):2206-16

54. Nieman DC, Henson DA, Austin MD, Sha W. Upper respiratory tract infection is reduced in physically fit and active adults. Br J Sports Med. 2011:45(12):987-92

55. Fondell E, Lagerros YT, Sundberg CJ, Lekander M, Balter O, Rothman KJ, Balter K. Physical activity, stress, and self-reported upper respiratory tract infection. Med Sci Sports Exerc. 2011;43(2):272-9.

56. Nieman DC, Henson DA, Austin MD, Brown VA. Immune response to a 30minute walk. Med Sci Sports Exerc. 2005;37(1):57-62.

57. Sloan CA, Engels HJ, Fahlman MM, Yarandi HE, Davis JE. Effects of exercise on S-IGA and URS in postmenopausal women. Int J Sports Med. 2013:34(1):81-6.

58. Martins RA, Cunha MR, Neves AP, Martins M, Teixeira-Verissimo M, Teixeira AM. Effects of aerobic conditioning on salivary $\lg A$ and plasma $\lg A$, IgG and IgM in older men and women. Int J Sports Med. 2009;30(12):906-12.

59. Bishop NC, Gleeson M. Acute and chronic effects of exercise on markers of mucosal immunity. Front Biosci (Landmark Ed). 2009;(14):4444-56.

60. Hemila H, Virtamo J, Albanes D, Kaprio J. Physical activity and the common cold in men administered vitamin E and beta-carotene. Med Sci Sports Exerc. 2003;35(11):1815-20.

61. Chubak J, McTiernan A, Sorensen B, Wener MH, Yasui $Y$, Velasquez M, Wood B, Rajan KB, Wetmore CM, Potter JD, et al. Moderate-intensity exercise reduces the incidence of colds among postmenopausal women. Am J Med. 2006;119(11):937-42.

62. Sun $Y$, Wang $Z$, Zhang $Y$, Sundell J. In China, students in crowded dormitories with a low ventilation rate have more common colds: evidence for airborne transmission. PLoS One. 2011:6(11):e27140. 